\title{
Glimpses of educational transformation
}

\section{Making choices at a turning point}

\author{
Bridget S. Somekh \\ The Manchester Metropolitan University, 799 Wilmslow Road, M20 2RR, UK; \\ b.somekh@mmu.ac.uk
}

\begin{abstract}
This paper is based on the study of four separate evaluations of the implementation of Information and Communication Technology (ICT) policies in schools in England during 1998-2002. The education system was in transition with new equipment coming into schools and patterns of computer use changing radically as a result of the Internet and school intranets. The most significant impact appeared to result from children's extended access to computers in the home. Children were using ICT in exploratory and innovative ways for leisure activities through which they were rapidly acquiring advanced skills. They also had the kind of sophisticated understanding of the role of computers in today's world that is a necessary condition of being able to envisage possible ways of using ICT for maximum benefit. The paper comes to the conclusion that a more radical approach to re-structuring the education system is necessary.
\end{abstract}

Key words: change, social contexts, sites of learning, policy, evaluation

\section{INTRODUCTION}

Between 1998 and 2002, a period of the steep upward curve in the exponential growth of technologies that started twenty or so years ago, digital technologies have entered the home and work lives of most people in the UK. The extraordinary shift in the patterns of human activity in the home and the workplace suggests that currently there are unparalleled opportunities for radical changes in schools and the education system. The system of schooling has proved resistant to reform in the last quarter century. The vision of politicians that technology would transform education has not so far been realised. Maybe we stand now at a turning point where there are

The original version of this chapter was revised: The copyright line was incorrect. This has been corrected. The Erratum to this chapter is available at DOI: 10.1007/978-0-387-35668-6_17 
two possible ways forward for the education system: Evolutionary change to the current system in line with larger changes in our society, or the sweeping away of schools as we know them to be replaced by an anarchic mix of online courses, student self-help and fragmentation of the state provision of education. What are the signs that our state education systems are capable of radical evolutionary change?

\section{GOVERNMENT ICT-ORIENTED INITIATIVES}

The UK government has invested heavily in networked technologies for schools in the last five years. Investment in the National Grid for Learning (NGfL), launched in 1998, totalled $£ 657$ million by 2002 and a further $£ 710$ million has been allocated to continue its development through 2002-4. In addition, $£ 180$ million was made available for teacher training through the New Opportunities Fund (NOF) (Somekh, et. al. 2001b). Progress was driven by a set of explicit targets: First, that all schools, colleges, universities and public libraries and as many community centres as possible would be connected to the NGfL by 2002; second, that Britain would become a centre of excellence in the development of networked software content.

Three other targets were also addressed: Ensuring the development of teachers' confidence and competence to teach using ICT; enabling school leavers to have a good understanding of ICT, with measures in place for assessing their competence in it; and a move to paperless communications between government and education bodies (DfES 2002). By 2001 the first targets had been almost achieved: 99 percent of secondary, 96 percent of primary and 97 percent of special schools were connected to the Internet. Seventy-one percent of secondary, 37 percent of primary and 33 percent of special schools had their own web sites (Somekh, et. al. 2001b). A consultation paper, published in May 2001 set out detailed proposals to consolidate progress on the second target. The NGfL portal was to be upgraded to establish a substantial resource of online educational materials, Curriculum Online (DfEE 2001). Although not all fully achieved, the five targets presented a coherent vision for increasing use of ICT in schools.

Alongside the investment in infrastructure and focus on achieving measurable targets, there has been a vision of entitlement to ICT as a means of increasing the life chances of all young people regardless of their families' socio-economic circumstances. David Blunkett, then Secretary of State for Education and Employment, said in a speech in 1998: "The involvement of the family in the learning process and the links between home and school are vital to the success we are seeking in raising standards and providing real equality of opportunity" (Pickering 2000). ICT was seen 
by government as a mechanism to link home and school and give parents and families access to educational materials. The E-Learning Foundation and Computers Within Reach were set up to place computers in the homes of disadvantaged families. To capitalise on the enthusiasm and motivation of children for ICT, in 2001 the DfEE set up a public-private partnership with strong links to the National Curriculum, partnering Channel 4 Television, Oracle Inc. and Intuitive Media to develop GridClub, "an educational fun site" for 7-11 year-olds.

Implementation of the policies has been monitored and evaluated by a series of government-funded research projects. This paper draws on four of them: ImpaCT2, the evaluation of the impact of ICT on students' attainment (co-directed by Colin Harrison, University of Nottingham, Peter Scrimshaw, Open University and Bridget Somekh, Manchester Metropolitan University); Pathfinders, the evaluation of the rollout of the NGfL in ten Pathfinder local education authorities (three strands led by Ros Sutherland, University of Bristol, Colin Harrison, University of Nottingham and Don Passey, University of Lancaster with Bridget Somekh, MMU as synoptic evaluator); ICTHOS, research into the use of ICT to enhance home-school links (Bridget Somekh, Diane Mavers and Cathy Lewin, MMU); and evaluation of the GridClub web site (Bridget Somekh and John Robinson, MMU, and Peter Scrimshaw, independent consultant).

\section{THE IMPACT OF ICT ON EDUCATION}

\subsection{The education system in transition}

Evidence from the ImpaCT2 project (Harrison, et. al. 2001; Harrison, et al. 2002) shows that during 2000-02 the education system was in transition. There was a time lag between the allocation of funds by central government and the installation of networks by the local education authority (LEAs) together with the arrival of new machines in schools. Some schools began to receive a significant amount of new equipment during 2000 but often the new machines were unfamiliar PCs replacing Acorn machines. Evidence from the Pathfinder evaluation (Somekh, et. al. 2001a; Somekh, et al. 2002) showed that some teachers who had been regular users of ICT saw that the move to PC networks in 2000 meant it was no longer possible to use "legacy" software. In primary schools stand-alone machines in individual classrooms were replaced by computer suites with an intranet connected to the Internet. For many primary schools the arrival of the intranet meant that they had to manage a server for the first time. 
In their preliminary reports in March 2000, describing the use of ICT in their schools, the ImpaCT2 teacher-researchers revealed a mixture of excitement and frustration (Harrison, et al. 2002). There was an expectation that the new resource would be of great value but schools were disrupted by cable-laying and re-allocation of rooms to make space for suites. The tradition of ICT use was itself disrupted and new routines of use had not yet been established.

By 2002, networked technologies were becoming established in some schools and primary teachers were markedly more confident in their use, perhaps as a result of using ICT suites and working with a ratio of 2:1 computers per child (or sometimes 1:1) for the first time. However, schools continued to battle with the logistics of moving children and teachers to computer suites.

\subsection{The school-based acquisition of ICT skills}

It is assumed by the majority of teachers that children need to be taught ICT skills. The installation of computer suites in primary schools has made the teaching of skills much easier for teachers, many of whom still declare themselves to be tentative users of ICT. There is also a desire not to discriminate in favour of children who have computers at home, which has led to an institutional blindness to their home-based achievements (Somekh, et. al. 2001b). For some children skills teaching is unnecessary and probably dull.

The guidelines from the Qualifications and Curriculum Authority, used by many primary schools, encourage a pattern of use to ensure that schools enable children to achieve the National Curriculum attainment targets for ICT. Suggested lessons integrate the teaching of skills with authentic uses of ICT for learning. In practice, the data suggest that the emphasis of both teachers and children is on skills acquisition rather than using ICT to learn subject knowledge. From survey responses (Somekh, et al. 2002) it is clear that children believe that the purpose of using computers in school is to acquire skills and classroom observations (Somekh, et. al. 2001a) show that, even when teachers set out with the intention of using computers for subject learning, all their verbal interactions with children are about how to operate the computer rather than the topic of study identified in the lesson plan.

\subsection{Considerable use of word processors}

Both Pathfinders and ImpaCT2 research showed that the most frequent use of computers in primary schools was for word processing, which 
produced smart copies of writing, often for display purposes. However, ICTHOS pupils in a middle school (9-13 year-olds) were highly motivated by using their laptops for writing both at home and at school. The ImpaCT2 final report (Harrison, et al. 2002) recommended that teachers should have specialist training in using word processors as tools to improve writing rather than merely as presentational tools. Given their popularity in primary schools it seems certain that word processors could have a major impact on the quality of children's writing if teachers had a better understanding of how they could be used.

\subsection{Learning difficult concepts}

One of the glimpses of the power of ICT to transform learning was revealed in evidence from ImpaCT2. Six teacher researchers working with the 9-11 year old children described a variety of uses of ICT for science teaching (Harrison, et al. 2002). They emphasised the way ICT helped children learn difficult concepts:

It was very beneficial because the interactive nature of CD-ROMs means that difficult concepts can be explained and if schools have limited resources, the children can observe a practical investigation taking place instead of just reading about it. The Internet can be also used to demonstrate practical investigations. Some software allows children to test their ideas and their outcome and change variables in the activity. Any gaps in the science curriculum are easy to fill like this or it's possible to revisit previous concepts - children enjoy this type of presentation. (Honeypot Lane Primary School)

\subsection{Needing to read}

Some of the ImpaCT2 teacher researchers reported in 2000-01 that it was difficult to use the Internet with primary-aged children if they did not have sufficiently good reading skills (Harrison, et al. 2002), a finding that may have very positive implications for learning. The Pathfinder evaluation showed a significant increase between 2000 and 2001 in the number of children who reported that computers "helped them with reading", coinciding with a significant increase in the levels of Internet use (Somekh, et al. 2002), giving another glimpse of the potential of ICT to transform learning. A "need to read" phenomenon may prove to be very beneficial in raising levels of achievement in reading. Boys may be able to engage in screen reading without arousing negative peer group pressure. 


\subsection{Innovative use of ICT in the home}

ImpaCT2, Pathfinders and ICTHOS all provided considerable evidence of children's enthusiasm for using computers and the Internet in their own homes. This confirmed the findings from earlier work in Australia and the UK (Downes 1996; 1999; Sutherland, et al. 2000; Facer, et al. 2001). Accounts of their use of ICT at home, written by primary children for the Pathfinders project, showed a very wide range of innovative, exploratory activities, often carried out alone, but sometimes with the assistance of family or friends. Children reported a rather higher rate of things "going wrong" at home, often because they were attempting to accomplish tasks requiring high levels of technical skill - tasks that were potentially much more rewarding than the ICT-based work they were allowed to do at school (Somekh, et al. 2002).

In the GridClub evaluation, primary children working with the team as Young Evaluators have demonstrated extraordinarily high levels of expertise with ICT (Mavers 2002). On the rare occasions when we have been able to observe children engaging in innovative special ICT projects at school they have demonstrated their ability to work creatively at a very high level, both technically and conceptually. While "exceptional" children tend to be more likely to be offered exceptional opportunities, the evidence suggests that all children would benefit from being encouraged to use computers in the more open-ended ways they use them at home.

In the course of working with children in all four projects, both through formal data collection, informal conversations and collaborative work with children as researchers, it was clear that they are rapidly acquiring skills in the use of digital technologies. ImpaCT2 data showed that by June 200185 percent of 10-11 year olds had a computer at home and 66 percent were connected to the Internet. On average, children spend three times as long on ICT in the home as they do at school (Harrison, et al. 2002). Pathfinders data showed that children are engaging in challenging and innovative uses of ICT in the home for their own leisure purposes (Somekh, et al. 2002).

\subsection{Play and games}

The ImpaCT2 and Pathfinder surveys established that the most popular computer-based activity for children is "playing games". Most schools have rules forbidding games playing which means that children report less frequent games playing at school than at home.

The really interesting issue here is the power of games for learning. Adult assumptions about games being "mindless" need to be challenged. The Pathfinders survey data (Somekh, et al. 2002) shows a strong correlation 
between games playing and children's belief that computers "help" with some critically important mathematical skills such as "visualising 3-D images in your mind" and "calculating".

Many educational activities are presented to children in a games format. Often these are of poor quality and cannot compete for children's attention with the products they can buy on CD-ROM or download from the Internet. The GridClub portal, however, provides children with interactive games produced by media and software experts with a background in the entertainment industry <www.gridclub.com>. Although the evaluation of GridClub is not complete evidence suggests that the games provide powerful learning opportunities for children.

There is also evidence that researchers need to be very careful in interpreting children's answers to questions about "games" and "learning" in relation to their use of computers. Children's experience has taught them to make much cruder categorisations of their computer-based activities than researchers may realise. From their enculturation at school and at home children appear to assume that activities that are fun and enjoyable are "games"; and "learning" only refers to what teachers are teaching them at school. Hence one 10 year-old boy, who said that in one week he spent seven hours using a computer at home and one hour at school, at first categorised all his home use as "games". However his responses to further questions showed that they were games from which he would certainly have been learning something of value. For example, on Monday he said: "I went on the Internet and got pictures," and on Wednesday and Thursday he spent a total of two hours playing "a manager game" - "managing" the Liverpool football club. On Thursday he spent half an hour on a game called Sensible Soccer and on Friday he "played on a game where you could make your own music."

\section{CONFLICTING POLICY INITIATIVES}

The NGfL is only one of many UK policy initiatives for education. If it is not clear to teachers how the initiatives can be integrated, they compete with one another for time. ImpaCT2 teachers leading research activities in the school said they reduced the amount of time they spent using computers in their teaching as a result of two other initiatives introduced at around the same time: the National Numeracy Strategy (NNS) and the National Literacy Strategy (NLS). The recommended teaching methods for the NLS and NNS include a large element of "whole class teaching" with the teacher engaging all the children's attention from the front of the class. Teachers said they 
found the initiative's requirements incompatible with using ICT (Harrison, et al. 2001).

Under our present system, teachers need to ensure that children will be able to demonstrate that they have achieved National Curriculum attainment targets at the expected levels. Although the pressure is greatest for literacy and numeracy, the National Curriculum places an emphasis on the teaching of subject knowledge in preparation for national tests. The majority of teachers have given no consideration to the benefits that ICT offers as a means of supporting open-ended project work or exploratory creativity.

\subsection{Challenges to educational tradition}

In reporting that there was "no time" to use computers when preparing children for national tests, teacher researchers in ImpaCT2 were embodying a resistance in the education system to disruption of established traditions. The assumptions embedded in the assessment system are antithetical to the new opportunities that ICT offers for learning. Many teachers felt that it would be irresponsible to spend much time using computers when preparing children to be assessed on hand-written tests. It was not merely that traditional forms of assessment place emphasis on hand-writing and spelling, which are unimportant when using a computer; traditional forms of assessment also give no credit for the acquisition of new skills such as finding information on the Internet, selecting for relevance, down-loading, processing and presenting it. In fact, the skills raise major problems in relation to traditional forms of assessment, which have depended upon the production of hand-written scripts under examination conditions to prevent any possibility of "plagiarism" or "cheating". Yet, as a parent said when discussing plagiarism with a researcher in the ICT and Home-School Links project (ICTHOS): "It's perhaps a different approach to education - to assimilate what's outside there and put it together for the purpose in view. I think that's a higher level skill which doesn't develop at the same pace - a more subtle approach to learning" (Somekh, et. al. 2001b).

\section{THE NEED FOR RADICAL CHANGE}

The evidence from the four evaluation projects strongly suggests that there is a need for radical change in the education system. Too many assumptions in the present system work against the kind of transformation in schooling and learning which ICT makes possible and which is observable in children's use of ICT in the home. Until recently, NGfL policy has not aimed at radical change but at improving children's standards of attainment 
in the National Curriculum in the UK. The policy conflicts with the nature of digital technologies, which offer new ways of learning new things within different structures.

Currently there is an awareness among UK policy-makers of the need for more fundamental change, for example in discussion of "the school of the future" as the venue for an ICT-rich learning environment in the 21st century' (DfEE 2001). But we are dealing with long established traditions and in-built assumptions about teachers' and students' roles and responsibilities, the value of students' accumulating facts and skills through traditional whole class teaching, and the "gold standard" of high grades in a formal system of national tests and examinations, hand-written in silence without access to technology tools or interaction with others. Our society as a whole subscribes to many of these traditions. It will require considerable vision and courage to turn such a system around.

\section{REFERENCES}

DfEE (2001) Curriculum Online - A Consultation Paper. London: Department for Education and Employment.

DfES (2002) Transforming the Way We Learn. Norwich: Department for Education and Skills.

Downes, T. (1996) The computer as a toy and a tool in the home: Implications for schools and teachers. Education and Information Technologies $13 / 4$ 191-201.

Downes, T. (1999) Playing with computing technologies in the home. Education and Information Technologies 4 1 1-15.

Facer, K., Furlong, J., Sutherland, R. and Furlong, R. (2001) Home is where the hardware is: Young people, the domestic environment and 'access' to new technologies. In I. Hutchby and J. H. Moran-Ellis (eds.) Children, Technology and Culture. London: Falmer Press 1327.

Harrison, C., Fisher, T., Haw, K., Lewin, C., McFarlane, A., Mavers, D., Scrimshaw, P. and Somekh, B. (2001) ImpaCT2: Emerging Findings from the Evaluation of the Impact of Information and Communications Technologies on Pupil Attainment. London: Department for Education and Skills.

Harrison, C., Fisher, T., Haw, K., Lewin, C., Mavers, D., Scrimshaw, P. and Somekh, B. (2002) ImpaCT2 Final Report (draft). Coventry: Becta.

Mavers, D. (2002) The Internet from a child's perspective. A paper presented at the IFIP Working Group 3.5 conference. Manchester, UK, June 29 -1uly 5, 2002.

Pickering, I. (2000) Whose child is it anyway? Managing Schools Today. November/December 2000 19-20.

Somekh, B., Barnes, S., Triggs, P., Sutherland, R., Passey, D., Holt, H., Harrison, C., Fisher, T., Joyes, G. and Scott, R. (2001a) NGfL Pathfinders: Preliminary Report on the Roll-out of the NGfL Programme in Ten Pathfinder LEAs. London: Department for Education and Skills.

Somekh, B., Mavers, D. and Lewin, C. (2001b) Using ICT to Enhance Home-School Links: An Evaluation of Current Practice in England. London: Department for Education and Skills. 
Somekh, B., Barnes, S., Triggs, P., Sutherland, R., Passey, D., Holt, H., Harrison, C., Fisher, T., Flett, A. and Joyes, G. (2002) Second Preliminary Report on the Roll-out of the NGfL Programme in Ten Pathfinder LEAs (Draft).

Somekh, B. and Davies, R. (1991) Towards a pedagogy for Information Technology. The Curriculum Journal 22 153-170.

Sutherland, R., Facer, L., Furlong, R. and Furlong, J. (2000) A new environment for education? The computer in the home. Computers and Education. Special Edition 34 195212.

\section{BIOGRAPHY}

Bridget Somekh has been researching the uses of ICT in education since 1984 when she experimented with using a computer to teach writing in her own classroom with 11-year-olds. She is currently Professor of Educational Research at Manchester Metropolitan University, UK. She has worked closely with teachers in collaborative Action Research projects and is an experienced evaluator of ICT programmes. Her books include Using IT Effectively in Teaching and Learning: Studies in Pre-service and In-service Teacher Education edited with Niki Davis (Routledge 1997) and Teachers Investigate Their Work: An Introduction to the Methods of Action Research co-authored with Herbert Altrichter and Peter Posch (Routledge 1993). In the last five years Bridget has been an invited keynote speaker on ICT in education at conferences in the USA, Brazil, Brussels (the European Commission), Hong Kong, Hungary, Norway, Portugal and Singapore. She is a member of IFIP's Working Group 3.5. 